Canadian

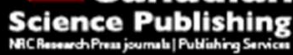

Canadian Geotechnical Journal Revue canadienne de géotechnique

\title{
ACCURACY OF DETERMINING PRE-CONSOLIDATION PRESSURE FROM LABORATORY TESTS
}

\begin{tabular}{|r|l|}
\hline Journal: & Canadian Geotechnical Journal \\
\hline Manuscript ID & cgj-2016-0203.R1 \\
\hline Manuscript Type: & Article \\
\hline Date Submitted by the Author: & 22-Oct-2016 \\
\hline Complete List of Authors: & $\begin{array}{l}\text { Umar, Muhammad; University of Western Ontario, Civil and Environmental } \\
\text { Engineering } \\
\text { Sadrekarimi, Abouzar; University of Western Ontario, }\end{array}$ \\
\hline Keyword: & Clay, pre-consolidation pressure, consolidation test, Compressibility \\
\hline \multicolumn{2}{|c}{} \\
\hline
\end{tabular}

SCHOLARONE ${ }^{m}$

Manuscripts 


\section{ACCURACY OF DETERMINING PRE-CONSOLIDATION PRESSURE FROM LABORATORY TESTS}

Muhammad Umar, Graduate Student, Department of Civil and Environmental Engineering, Western University, London, Canada, Email: mumar3@uwo.ca

Abouzar Sadrekarimi, Ph.D., P.Eng., Assistant Professor and Principal Investigator, Department of Civil and Environmental Engineering, Western University, London, Canada. Tel: +1 (519) 661-2111 (Ext.80334), Email: asadrek@uwo.ca

A revised paper submitted for review and publication in the Canadian Geotechnical Journal

October 2016 


\title{
ACCURACY OF DETERMINING PRE-CONSOLIDATION PRESSURE FROM \\ LABORATORY TESTS
}

\begin{abstract}
Shear strength and compressibility of fine-grained soils is strongly influenced by their stress history and the maximum (pre-consolidation) pressure $\left(\sigma_{p}^{\prime}\right)$. Accurate determination of $\sigma_{p}^{\prime}$ is thus critical for settlement and stability analysis involving fine-grained soils. Many graphical techniques are available for estimating $\sigma_{p}^{\prime}$ from the interpretation of soil compression in laboratory consolidation (oedometer) tests. However, the accuracy of these methods has not been extensively proven or compared with each other. A series of 30 laboratory oedometer tests is carried out in this study based on controlled-rate of strain and incrementally-loaded testing techniques. Several Canadian clay specimens are subject to cycles of one-dimensional compression loading and unloading in order to produce a known stress history and $\sigma_{p}^{\prime}$. The imposed $\sigma_{p}^{\prime}$ are compared with the predictions of 11 methods for determining $\sigma_{p}^{\prime}$. The accuracies of these methods are subsequently evaluated by comparing their predictions with $\sigma_{p}^{\prime}$ imposed during the consolidation experiments. While these methods mostly overestimate $\sigma_{p}^{\prime}$, it is determined that a bi-logarithmic graphical approach based on the slopes of the virgin compression and recompression segments of soil compression curve provides the most accurate predictions of $\sigma_{p}^{\prime}$. The potential ranges of errors associated with the application of each method are also presented.
\end{abstract}

Keywords: clay, pre-consolidation pressure, laboratory consolidation test, plasticity, compressibility 


\section{Introduction}

Compressible fine-grained soils often exhibit a memory of the past stress history which they have experienced. This memory of soils is often presented by the pre-consolidation pressure corresponding to the maximum effective stress ever experienced by a particular soil (Becker, et al. 1987; Burland, 1990; Casagrande, 1936). Different stress histories can be naturally generated from a soil's geological stress history, soil erosion, desiccation, excavation, melting of glaciers, cementation, and sustained seepage forces.

Pre-consolidation pressure (denoted here by " $\sigma_{p}^{\prime}$ ") is a pseudo-elastic limit which separates 'elastic' pre-yield from 'plastic' post-yield behaviour of a soil. This is a key parameter in geotechnical engineering for analyzing and predicting settlement behavior, overconsolidation ratio, stress history, and short-term stability problems in soft clays (Jamiolkowski, et al. 1985; Ladd and Foote 1974; Mesri and Godlewski 1977; Wroth 1984). The results of these analyses could be questionable if there is significant uncertainty and inaccuracy in determining the value of $\sigma_{p}^{\prime}$. Therefore, a reliable method that would provide accurate estimates of $\sigma_{p}^{\prime}$ is central to geotechnical engineering analysis and design in fine-grained soils.

Pre-consolidation pressure is often determined from the results of one-dimensional consolidation tests ("Oedometer tests"). Numerous empirical methods have been developed in the past for interpreting $\sigma_{p}^{\prime}$ of compressible soils from standard oedometer tests (Becker et al. 1987; Boone 2010; Burland 1990; Butterfield 1979; Casagrande 1936; Jacobsen 1992; Janbu 1967; Jose, et al. 1989; Oikawa 1987; Onitsuka et al. 1995; Pacheco Silva 1970; Sridharan 1991; Wang and Frost 2004). This study presents a comprehensive evaluation of the accuracy of these methods for interpreting $\sigma_{p}^{\prime}$ based on a large set of controlled-rate of strain (CRS) and incrementally-loaded (IL) consolidation tests on clay specimens with known stress histories. This is different than 
some other investigations in which the pre-consolidation pressure was unknown or limited comparisons were made based on indirect estimations of $\sigma_{p}^{\prime}$ from undrained strength or other empirical methods (Boone 2010; Schmertmann 1955; Wang and Frost 2004).

\section{Empirical Methods for Predicting $\sigma_{p}^{\prime}$}

The current approaches for determining soil pre-consolidation pressure from oedometer consolidation tests are all based on graphical interpretation procedures of void ratio $(e)$ versus effective vertical stress $\left(\sigma_{v}^{\prime}\right)$ data. Table 1 provides a brief summary of these methods and their application procedures. While the classical method of Casagrande (1936) is based on fitting consolidation data with a bilinear void ratio and $\log \left(\sigma_{v}^{\prime}\right)$ curve, several other investigators have proposed alternative forms of semi- or bi-logarithmic graphs for determining $\sigma_{p}^{\prime}$. Compared to semi-logarithmic plots, plotting void ratio and $\sigma_{v}^{\prime}$ in a bi-logarithmic scale (Butterfield 1979; Oikawa 1987; Onitsuka, et al. 1995) can be advantageous by producing better linear relationships between $\log (1+e)$ and $\log \left(\sigma_{v}^{\prime}\right)$. Note that although Sridharan et al. (1991) proposed an equal approach to that of Oikawa (1987), but here reference is made to Oikawa (1987) because of its earlier development.

As soil stiffness evolves from small strains to large strains near $\sigma_{p}^{\prime}$, Janbu (1967) suggested determining $\sigma_{p}^{\prime}$ based on the reduction of constrained modulus $(M)$ at $\sigma_{p}^{\prime}$. Since lateral strains are prevented in an oedometer test, constrained modulus can be directly calculated from the ratio of load increment $\left(\delta \sigma_{\mathrm{v}}^{\prime}\right)$ to the increment of volumetric strain $\left(\delta \varepsilon_{\mathrm{vol}}\right)$. Janbu $(1967)$ does not specify the detailed procedure for determining $\sigma_{p}^{\prime}$, although some clarification is provided by Lunne et al. (2008). 
Becker et al. (1987) suggested the concept of using the amount of strain energy (i.e. work) imposed on a soil specimen for determining $\sigma_{p}^{\prime}$ from oedometer consolidation tests. In this method arithmetic linear relationships are approximately fitted for the cumulative work applied per unit volume of a specimen (i.e. strain energy) and effective stress data from consolidation tests. The pre-consolidation pressure is defined at the point of intersection of the initial fitted line and the linear relationship observed at higher stresses. More recently, Wang and Frost (2004) suggested to use plastic (irrecoverable) deformations (instead of the total deformation) in order magnify the contrast between soil consolidation behavior before and after $\sigma_{p}^{\prime}$ and employ the slope of the unloading-reloading curve to reduce sample disturbance effects. They show that the dissipated strain energy provides a better representation of soil yielding and hardening behavior. As summarized above, based on the parameters selected for plotting and presenting consolidation data, the existing methods for determining $\sigma_{p}^{\prime}$ can be categorized into four broad groups of: A) semi-logarithmic, B) bi-logarithmic, C) constrained modulus, and D) strain energy (work) procedures. All of the aforementioned methods implicitly assume that a particular soil exhibits a unique relationship between void ratio and $\sigma_{v}^{\prime}$ at the end of primary consolidation (Mesri and Choi 1985; Schmertmann 1955).

\section{Experimental Procedure}

A comprehensive series of 23 controlled-rate of strain (CRS) and 7 incrementally-loaded (IL) one-dimensional consolation tests were carried out on two Canadian clay soils. CRS tests were employed to apply a continuous and controlled consolidation load on a soil specimen and provide a more precise measurement of soil consolidation behavior (Sheahan and Watters 1997). In order to build-in a known $\sigma_{p}^{\prime}$, the specimens were subjected to cycles of consolidation loading 
to a predetermined $\sigma_{p}^{\prime}$, unloading and then reloading. The details of the experiments are described below.

\section{Tested Clays}

A number of block samples of Port Colborne and Sombra silty clays and several thin-walled tube samples of another silty clay from North Toronto were tested in this study. Laboratory tests including Atterberg limit, sieve analysis, and hydrometer tests were carried out on these samples according to the ASTM standard procedures (ASTM 2007,2010). Scanning Electron Microscopy (SEM) and X-ray Diffraction (XRD) analyses were also conducted on several specimens in order to determine their composition and mineralogy. Based on these analyses, it was determined that Port Colborne and Sombra clay samples were essentially composed of Kaolinite and Illite particles, whereas the North Toronto silty clay was mostly made of carbonates, followed by feldspar, quartz, Kaolonite, and Illite particles. As shown in Table 2, plasticity indices (PI) of the samples range from 9 to 24 , with initial water contents $\left(\omega_{o}\right)$ of $19 \%$ to $52 \%$. According to the Unified Soil Classification System (ASTM 2011b), the samples were low plasticity clays (CL).

\section{Specimen Preparation}

Trimming of the specimens to fit the consolidation ring was carefully done using a wire saw to minimize sample disturbance. A stainless steel consolidation ring (50 $\mathrm{mm}$ in diameter and 19 mm height) was then pushed slowly onto the specimens from its sharp edge. The inside surface of the consolidation ring was lubricated with low-friction silicon grease in order to minimize friction and specimen disturbance. A straightedge with a sharp cutting edge was used for the final trim and leveling both top and bottom surfaces of the specimen. Any small voids were carefully filled with remolded soil without disturbing the specimen. The consolidation ring and 
the soil were then carefully weighed for the accurate computation of void ratio at the beginning of each test. Excess soil was also used for determining water content and soil classification. Finally, a thin disc fitted on the consolidation ring was used to push the top surface of the specimen about $2 \mathrm{~mm}$ into the ring in order for the porous stone and the loading cap to properly seat on the specimen. The porous stones were saturated by boiling them in water for about 20 minutes prior to specimen preparation.

\section{IL Tests}

In order to minimize the effect of secondary compression and the development of quasipreconsolidation pressure (Leonards and Altschaeffl 1964; Mesri and Shahien 1994), incrementally-loaded (IL) consolidation tests were conducted following Method B of the ASTM standard procedure (ASTM 2011a). In these experiments, the axial stress was applied by dead weights via a lever ratio of 10 to 1 . The magnitude of the axial stress was increased stepwise at a load-increment ratio (LIR) of 1 and each load increment was sustained for 60 minutes at which the specimen deformation reached a stabilized low rate (indicating the completion of primary consolidation as determined from log-time constructions). Since the duration of secondary compression was minimized by adopting short (60 minutes) load increment durations (instead of 24 hours waiting periods typically used in consolidation testing), the void ratio at the end of each load increment was used for constructing a consistent End-of-Primary (EOP) consolidation diagram as recommended by the ASTM standard procedure. 


\section{CRS Tests}

CRS tests were carried out using an automated computer-controlled apparatus (manufactured by GEOTAC TRAUTWEIN, Texas, USA) following the ASTM D4186 standard procedure (ASTM 2012). The CRS apparatus includes an axial loading frame, a servo-controlled axial loading jack, pore water pressure and displacement (LVDT) transducers, and a CRS consolidation cell. After specimen preparation, the CRS cell was filled with deaired water for the application of cell pressure and the bottom pore pressure transducer was flushed and saturated to measure excess pore water pressure. A back-pressure was then applied in order to saturate the specimen. Prior to consolidation loading, the base drain valve was closed and the initial pore water pressure was recorded to evaluate specimen saturation. A pore pressure parameter $(B)$ value of $98 \%$ or higher was achieved in all experiments. The specimen was subsequently consolidated by applying an axial load at a constant-strain rate while time, axial deformation, normal stress, and specimen base pore water pressure were measured. According to the ASTM standard method (ASTM 2012), a strain rate should be selected to produce a base excess pore pressure ratio of $3 \%$ to $15 \%$ at the end of the loading phase in order to measure hydraulic conductivity and the coefficient of consolidation. Therefore, trial tests were performed in order to determine the appropriate strain rate for each soil type. As a result, Port Colborne and Sombra clay specimens were loaded at constant strain rates of $1.5 \% / \mathrm{hr}$ and $0.5 \% / \mathrm{hr}$, respectively. However, because of the high carbonate content, lower PI, and relatively more permeable specimens of the North Toronto silty clay, very little excess pore pressure developed even at a higher strain rate of $5 \% /$ hour. Greater strain rates $(>5 \% / \mathrm{hr})$ however were not employed in order to comply with the ASTM standard (ASTM 2012) and avoid strain rate and dynamic loading effects. Moreover, hydraulic conductivity and coefficient of consolidation measurements were not required for this study. 
Imposing Pre-consolidation Pressures

In both CRS and IL experiments, the specimens were loaded beyond their in-situ preconsolidation pressures $\left(\sigma_{p, o}^{\prime}\right)$ and therefore the effects of $\sigma_{p, o}^{\prime}$, in-situ fabric, and sample disturbance on the results of this study were eliminated. A pre-consolidation pressure $\left(\sigma_{p, i}^{\prime}>\right.$ $\sigma_{p, o}^{\prime}$ ) was built-in by maintaining a load for a period of 2 to 3 hours in order to complete primary consolidation and ensure full dissipation of excess pore water pressure. The specimens were unloaded and then consolidated (reloaded) to stresses exceeding $\sigma_{p, i}^{\prime}$. This procedure was repeated for some specimens in order to produce different $\sigma_{p, i}^{\prime}$ and evaluate the predictive methods for multiple magnitudes of $\sigma_{p, i}^{\prime}$. The ensuing consolidation behavior would thus reflect soil compressibility behavior without any effects of stress relief or fabric disturbance (Schmertmann 1955). Minor corrections were also made to account for equipment deflection (for CRS and IL tests) and piston uplift force (for CRS tests). At the end of the experiments, each specimen was unloaded, removed from the consolidation cell and its final mass and moisture content were determined.

\section{Experimental Results and Interpretations}

Table 3 summarizes the characteristics of the experiments, and Figs. 1 and 2 present typical endof-primary consolidation (EOP) $e-\log \left(\sigma_{v}^{\prime}\right)$ stress paths from the CRS and IL consolidation tests of this study. The graphical procedures of Table 1 are used to estimate the pre-consolidation pressures $\left(\sigma_{p}^{\prime}\right)$. For consistency, the same ranges of $\sigma_{\mathrm{v}}^{\prime}$ are chosen for recompression and compression segments (and their tangents) for each method. The pre-consolidation pressures $\left(\sigma_{p}^{\prime}\right)$ estimated for the experiments of Table 3 are summarized in Tables 4 to 6 . As examples, the 
applications of the graphical procedures of Table 1 are illustrated for CRS (for specimen P1) and IL (for specimen P7) tests in Figs. 3 and 4. Note that Janbu's procedure is quite sensitive to the slope of the $\sigma_{\mathrm{v}}^{\prime}-\varepsilon_{\mathrm{vol}}$ curve for determining M. As a result of the limited data points (in IL tests) and the large variation of $M$ with subtle changes in the slope of the $\sigma_{\mathrm{v}}^{\prime}-\varepsilon_{\mathrm{vol}}$ curve (in CRS tests), fitting of straight lines to the $M-\sigma_{v}^{\prime}$ plot was quite subjective and the determination of $\sigma_{p}^{\prime}$ became inconclusive for the soils of this study.

\section{Discussion}

Figs. 5 to 7 compare the imposed $\sigma_{p, i}^{\prime}$ with those predicted by the empirical procedures for each category of Table 1. CRS and IL consolidation tests data from several other studies (Becker et al. 1987; Grozic, et al. 2003; Grozic et al. 2005; Jose et al. 1989; Sridharan 1991) are also included in these figures in order to supplement the analyses of this study and extend the comparisons to a wider range of PI $(=9-87)$. The absolute errors for each predictive method are presented according to the following equation:

Absolute $\operatorname{Error}(\%)=\left|\sigma_{p}^{\prime}-\sigma_{p, i}^{\prime}\right|$

In which, $\sigma_{p}^{\prime}$ and $\sigma_{p, i}^{\prime}$ are the predicted and imposed (measured) pre-consolidation pressures, respectively. In general, as shown in Figs. 5 to 7, all methods tend to overestimate $\sigma_{p}^{\prime}$ which can lead to an unsafe stability analysis or the underestimation of consolidation settlement of structures overlying compressible clay deposits.

These plots further indicate comparatively higher inaccuracies in predicting $\sigma_{p}^{\prime}$ of samples with lower PI. This is due to the greater ambiguity in identifying the point of maximum curvature of 
these samples. For example, as illustrated in Fig. 2(b), a rounded curvature was observed in the $e$ $-\log \left(\sigma_{v}^{\prime}\right)$ consolidation plot of North Toronto silty clay specimen $(\mathrm{PI}=11.0)$ which produced a relatively gentle transformation from recompression to virgin compression behavior compared to the Port Colborne clay specimen $(\mathrm{PI}=14.8)$ in Fig. 2(a). The lack of a sharp curvature obscured the point of significant change in consolidation behavior and hence $\sigma_{p}^{\prime}$. More plastic clays (higher PI) exhibit sharp curvatures in $e-\log \left(\sigma_{v}^{\prime}\right)$ diagrams with well-defined breaks at the vicinity of $\sigma_{p}^{\prime}$ and this would produce an overall higher degree of accuracy.

In order to facilitate comparison of the overall accuracies of the methods employed in this study, the magnitudes of errors are aggregated using the Root Mean Square Error (RMSE) as below:

$R M S E=\sqrt{\frac{\sum_{1}^{n}\left(\sigma^{\prime} p, i-\sigma^{\prime} p\right)^{2}}{n}}$

RMSE presents the standard deviation (residuals) of the differences between $\sigma_{p}^{\prime}$ and $\sigma_{p, i}^{\prime}$ (Hyndman and Koehler 2006). Table 7 ranks the overall accuracies of the methods analyzed here based on each method's RMSE from both IL and CRS test results. The ranges and average magnitudes of errors $\left(\sigma_{p}^{\prime}-\sigma_{p, i}^{\prime}\right)$ are also provided for comparison, which can be used as a guideline for reporting the possible overestimation (positive error) or underestimation (negative error) of $\sigma_{p}^{\prime}$ determined from each of the empirical methods. Fig. 8 further provides a clearer comparison of the RMSE and average errors for all methods.

According to Table 7 and Fig. 8, the first seven methods (Becker, et al. 1987; Boone, 2010; Burland 1990; Butterfield 1979; Jose et al. 1989; Oikawa 1987; Onitsuka et al. 1995) show more-or-less comparable errors in predicting $\sigma_{p}^{\prime}$, with the Oikawa (1987) and Burland (1990) 
procedures providing the lowest overall RMSE and average error, respectively. These methods provided more accurate estimations of $\sigma_{p}^{\prime}$ (with lower average errors and RMSE), and hence their applications would be safer and more conservative. In fact, careful examination of data in Tables 4 to 6 indicates that these procedures (in particular Oikawa, Onitsuka et al. Butterfield, and Boone methods) provide similar estimates of $\sigma_{\mathrm{p}}^{\prime}$. Previous studies (Boone 2010; Grozic, et al. 2003; Jose et al. 1989; Onitsuka et al. 1995; Sridharan 1991) have often compared the accuracy of some of these methods based on different recompression and compression ranges of $\sigma_{\mathrm{v}}^{\prime}$ for each method and they have proposed an apparently improved graphical method using biased ranges of recompression and compression segments to show a higher accuracy. Whereas in this study, precisely the same recompression, compression, and maximum curvature points (for Casagrande and Jacobsen methods) are consistently used with all methods in order to make an unbiased comparison of $\sigma_{p}^{\prime}$ estimates.

The aforementioned methods are followed by Casagrande (1936), Pacheco Silva (1970), and Wang and Frost (2004) techniques with increasing RMSE and average errors. Note that $\sigma_{p}^{\prime}$ estimated based on Jacobsen's method displayed extremely large errors and they are not shown in the histograms of Fig. 8. Among the work/energy methods (in Fig. 7), Becker et al.'s method provides better predictions of $\sigma_{p}^{\prime}$ (with an average error of $15.6 \mathrm{kPa}$ ) compared to the newer and updated method of Wang and Frost (2004) displaying an average error of $23.5 \mathrm{kPa}$. Note that despite the smaller average error $(=15.6 \mathrm{kPa})$ of Becker et al.'s method, its greater range of deviation (164.1 to $-43.2 \mathrm{kPa}$ ) leads to its poorer overall RMSE and accuracy. Moreover, although Casagrande's method (with an average deviation of $33.1 \mathrm{kPa}$ ) is often recommended in most textbooks, codes (ASTM 2011a), and laboratory manuals, the accuracy of its predictions are among the lowest. The inferior accuracy of Casagrande's and Jacobsen's procedures is 
particularly associated with their high emphasize placed on data points close to $\sigma_{p}^{\prime}$ where the $e$ $\log \left(\sigma_{v}^{\prime}\right)$ curve displays it's greatest non-linearity. As a result, the perceived point of maximum curvature of the $e-\log \left(\sigma_{v}^{\prime}\right)$ data and hence the determination of $\sigma_{p}^{\prime}$ become dependent on the scale of the void ratio axis. The higher inaccuracy of Jacobsen's method is not surprising considering its arbitrary suggestion of $\sigma_{p}^{\prime}$ equal to 2.5 times the stress at the point of maximum curvature of the $e-\log \left(\sigma_{v}^{\prime}\right)$ diagram. These can significantly limit the confidence and reliability of $\sigma_{p}^{\prime}$ determination from these approaches, in particular by less experienced analysts and engineers. However, all of the other methods are free of these defects as they do not require the maximum curvature point.

Furthermore, as compared in Fig. 8, the continuous compression curves from CRS tests were generally effective in reducing the amount of errors in most methods. However, a number of methods (Boone 2010; Butterfield 1979; Pacheco Silva 1970; Wang and Frost 2004) show particularly greater errors in predicting $\sigma_{p}^{\prime}$ from IL tests that those from CRS tests. These methods are thus better suited for interpreting CRS tests which provide continuous data (compared to limited load increments in IL tests). One the other hand, Oikawa (1987), Jose et al. (1989), and Becker et al. (1987) exhibit similar performances in predicting $\sigma_{\mathrm{p}}^{\prime}$ from CRS and IL tests.

It is finally noted that cementation bonds and aging may develop during and after sedimentation in the field, and produce an apparent preconsolidation effect and increase the in-situ preconsolidation pressure (Lunne et al. 2006). On the other hand, disturbance during sampling, transportation and laboratory specimen preparation could partly destroy the effects of aging and cementation. Hence sample disturbance could partly compensate the general overestimation of 
$\sigma_{p}^{\prime}$ by the predictive methods examined here. Although, precise quantification of sample disturbance effects can be difficult and variable.

\section{Conclusions}

The accuracies of 11 methods for interpreting pre-consolidation pressure from laboratory consolidation tests were evaluated in this study. A total of 30 controlled-rate of strain (CRS) and incrementally-loaded (IL) consolidation tests were carried on three Canadian silty clays. Compared to incremental loading, CRS tests provided significantly more data points which facilitated the interpretation procedures and improved their overall prediction accuracy. The comparisons indicated that all methods would mostly overestimate $\sigma_{p}^{\prime}$, which can reduce the conservatism of settlement or stability analysis in fine-grained soils. The overall accuracy of $\sigma_{p}^{\prime}$ predictions improved with increasing plasticity (PI) because of the sharper curvature of the consolidation curve, and hence the higher confidence in detecting the point of maximum curvature from consolidation data.

The accuracies of $\sigma_{p}^{\prime}$ predictions from different methods were compared based on the aggregated root mean square errors (RMSE) as well as the averages and the ranges of errors for each method. Among the 11 methods examined in this study, a bi-logarithmic graphical technique suggested by Oikawa (1987) was found to provide the most accurate predictions of $\sigma_{p}^{\prime}$ with an average overestimation potential of $16.8 \mathrm{kPa}$. According to this method, $\sigma_{p}^{\prime}$ is simply established from oedometer tests at the intersection point of tangent lines to the recompression and compression segments of soil compression data in a $\log (1+\mathrm{e})$ versus $\log \left(\sigma_{\mathrm{v}}^{\prime}\right)$ plot. Oikawa's method therefore provided an ideal combination of simplicity, quick interpretation and improved accuracy, and it is recommended in this study for determining $\sigma_{p}^{\prime}$. This was verified by the 
extensive database of one-dimensional consolidation experiments on several clay samples in this study. Next to Oikawa (1987), a number of other bi-linear plotting methods also provided close estimates of the known pre-consolidation pressures. On the other hand, Casagrande (1936) classical method provided relatively inaccurate predictions of $\sigma_{\mathrm{p}}^{\prime}$, with an average deviation of $33.1 \mathrm{kPa}$. The average and the ranges of errors established in this study further provide an opportunity to recognize the potential inaccuracy of each method and devise adequate safety factors for settlement or stability analysis.

\section{References:}

ASTM 2007. "Standard D422: Standard Test Method for Particle-Size Analysis of Soils." Annual Book of ASTM Standards, ASTM International, West Conshohocken, PA. ASTM 2010. "Standard D4318: Standard Test Methods for Liquid Limit, Plastic Limit, and Plasticity Index of Soils." Annual Book of ASTM Standards, ASTM International, West Conshohocken, PA.

ASTM 2011a. "Standard D2435: Standard Test Methods for One-Dimensional Consolidation Properties of Soils Using Incremental Loading." Annual Book of ASTM Standards, ASTM International, West Conshohocken, PA.

ASTM 2011b. "Standard D2487: Standard Practice for Classification of Soils for Engineering Purposes (Unified Soil Classification System)." Annual book of ASTM Standards, ASTM International, West Conshohocken, PA.

ASTM 2012. "Standard D4186: Standard Test Method for One-Dimensional Consolidation Properties of Saturated Cohesive Soils Using Controlled-Strain Loading." Annual Book of ASTM Standards, ASTM International, West Conshohocken, PA. 
Becker, D. E., Crooks, J. H. A., Been, K., and Jefferies, M. G. 1987. "Work as a criterion for determining in situ and yield stresses in clays." Canadian Geotechnical Journal, 24, 549 $-564$.

Boone, S. J. 2010. "A critical reappraisal of “preconsolidation pressure"' interpretations using the oedometer test." Canadian Geotechnical Journal, 47, 281 - 296.

Burland, J. B. 1990. "On the compressibility and shear strength of natural clays." Geotechnique, 40(3), $329-378$.

Butterfield, R. 1979. "A natural compression law for soils (an advance on e-log p')." Geotechnique, 29(4), 469 - 480.

Casagrande, A. 1936. "Determination of preconsolidation load and its practical significance." First International Conference on Soil Mechanics and Foundation Engineering, Cambridge, Massachusetts, 22-26 June, 1936, 60 - 64.

Grozic, J. L. H., Lunne, T., and Pande, S. 2003. "An oedometer test study on the preconsolidation stress of glaciomarine clays." Canadian Geotechnical Journal, 40(5), $857-872$.

Grozic, J. L. H., Lunne, T., and Pande, S. 2005. "Reply to the discussion by Clementino on "An oedometer test study on the preconsolidation stress of glaciomarine clays"." Canadian Geotechnical Journal, 42(3), 975 - 976.

Hyndman, R. J., and Koehler, A. B. 2006. "Another look at measures of forecast accuracy." International Journal of Forecasting, 22(4), 679 - 688.

Jacobsen, H. M. 1992. "Bestemmelse af forbelastningstryk I laboratoriet." Nordiske Geotecknikermøde NGM-92, Aalborg, 28-30 May 1992, 455 - 460. 
Jamiolkowski, M., Ladd, C. C., Germaine, J. T., and Lancelotta, R. 1985. "New developments in field and laboratory testing of soils." Proc., Proceedings of the $11^{\text {th }}$ International Conference on Soil Mechanics and Foundation Engineering, A.A.Balkema, 57-153.

Janbu, N. 1967. "Settlement calculations based on the tangent modulus concept." Soil Mechanics and Foundation Engineering, The Technical University of Norway, Trondheim, 32.

Jose, B. T., Sridharan, A., and Abraham, B. M. 1989. "Log-Log method for determination of preconsolidation pressure." Geotechnical Testing Journal, ASTM, 12(3), 230 - 237.

Ladd, C. C., and Foote, R. 1974. "A new design procedure for stability of soft clays." Journal of the Geotechnical Engineering Division, ASCE, 100(GT7), 763 - 786.

Leonards, G. A., and Altschaeffl, A. G. 1964. "Compressibility of clay." Journal of Soil Mechanics and Foundations Division, ASCE, 90(SM5), 133 - 155.

Lunne, T., Berre, K. H., Andersen, M., Sjursen, M., and Mortensen, N. 2008. "Effects of sample disturbance on consolidation behaviour of soft marine Norwegian clays." Proc., Third International Conference on Site Characterization, ISC'3, Taylor \& Francis Group, London, UK, 1471 - 1479.

Lunne, T., Berre, T., Andersen, K. H., Strandvik, S., and Sjursen, M. 2006. "Effects of sample disturbance and consolidation procedures on measured shear strength of soft marine Norwegian clays." Canadian Geotechnical Journal, 43, 726 - 750.

Mesri, G., and Choi, Y. K. 1985. "The uniqueness of the end-of-primary (EOP) void ratioeffective stress relationships." Proceedings of International Conference of Soil Mechanics and Foundation Engineering (ICSMFE), San Francisco, 587-590.

Mesri, G., and Godlewski, P. M. 1977. "Time- and stress-compressibility interrelationship." Journal of the Geotechnical Engineering Division, 103(GT5), 417-430. 
Mesri, G., and Shahien, M. 1994. "Discussion: Preconsolidation versus aging behvaior of Kaolinite clay." Journal of Geotechnical Engineering, ASCE, 120(9), 1643 - 1645.

Oikawa, H. 1987. "Compression curve of soft soils." Soils and Foundations, 27(3), 99 - 104.

Onitsuka, K., Hong, Z., Hara, Y., and Shigeki, Y. 1995. "Interpretation of oedometer test data for natural clays." Soils and Foundations, 35(3), 61 - 70.

Pacheco Silva, F. 1970. "A new graphical construction for determination of the pre-consolidation stress of a soil sample." Proceedings of the $4^{\text {th }}$ Brazilian Conference on Soil Mechanics and Foundation Engineering, Rio de Janeiro, Brazil, 225 - 232.

Schmertmann, J. N. M. 1955. "The undisturbed consolidation behavior of clay." From Research to Practice in Geotechnical Engineering, Transactions of the American Society of Civil Engineers, American Society of Civil Engineers (ASCE), 1201-1233.

Sheahan, T. C., and Watters, P. J. 1997. "Experimental verification of CRS consolidation theory." Journal of Geotechnical and Geoenvironmental Engineering, ASCE, 123(5), 430 $-437$.

Sridharan, J. B. T. 1991. "Improved technique for estimation of preconsolidation pressure." Geotechnique, 41(2), 263 - 268.

Wang, L. B., and Frost, J. D. 2004. "Dissipated strain energy method for determining preconsolidation pressure." Canadian Geotechnical Journal, 41, 760 - 768.

Wroth, C. P. 1984. "The interpretation of in situ soil tests." Geotechnique, 34(4), 449 - 489. 


\section{Figure Captions}

Fig. 1: EOP consolidation curves for CRS consolidation tests P1 and S1 and the imposed preconsolidation pressures $\left(\sigma_{p, i}^{\prime}\right)$

Fig. 2: EOP consolidation curves for IL consolidation tests P7 and T5 and the imposed preconsolidation pressures $\left(\sigma_{p, i}^{\prime}\right)$

Fig. 3: Applications of (a) Casagrande (1936) and Jacobsen (1992), (b) Boone (2010) and Pacheco Silva (1970), (c) Burland (1990), (d) Butterfield (1979), (e) Oikawa (1987), (f) Jose et al. (1989), (g) Onitsuka et al. (1995), (h) Becker et al. (1987) and Wang and Frost (2004) methods for estimating $\sigma_{\mathrm{p}}^{\prime}$ in CRS specimen P1 subjected to $\sigma_{\mathrm{p}, \mathrm{i}}^{\prime}=98.3 \mathrm{kPa}$

Fig. 4: Applications of (a) Casagrande (1936) and Jacobsen (1992), (b) Boone (2010) and Pacheco Silva (1970), (c) Burland (1990), (d) Butterfield (1979), (e) Oikawa (1987), (f) Jose et al. (1989), (g) Onitsuka et al. (1995), (h) Becker et al. (1987) and Wang and Frost (2004) methods for estimating $\sigma_{p}^{\prime}$ in IL specimen P7 subjected to $\sigma_{p, i}^{\prime}=150.0 \mathrm{kPa}$

Fig. 5: Comparisons of (a) $\sigma_{p, i}^{\prime}$ with predictions, and (b) the ranges of absolute errors with PI for the semi-logarithmic methods

Fig. 6: Comparisons of (a) $\sigma_{p, i}^{\prime}$ with predictions, and (b) the ranges of absolute errors with PI for the bi-logarithmic methods

Fig. 7: Comparisons of (a) $\sigma_{p, i}^{\prime}$ with predictions, and (b) the ranges of absolute errors with PI for the strain energy methods

Fig. 8: Comparison of (a) RMSE and (b) average errors of different methods in predicting $\sigma_{\mathrm{p}}^{\prime}$ from CRS and IL tests. 


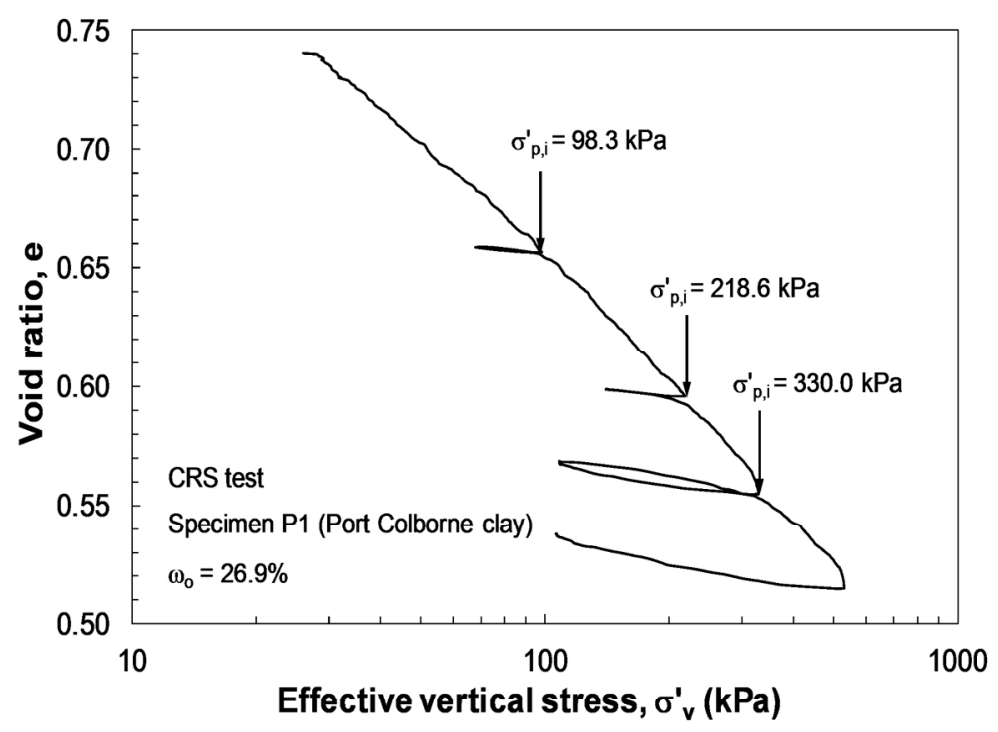

(a)

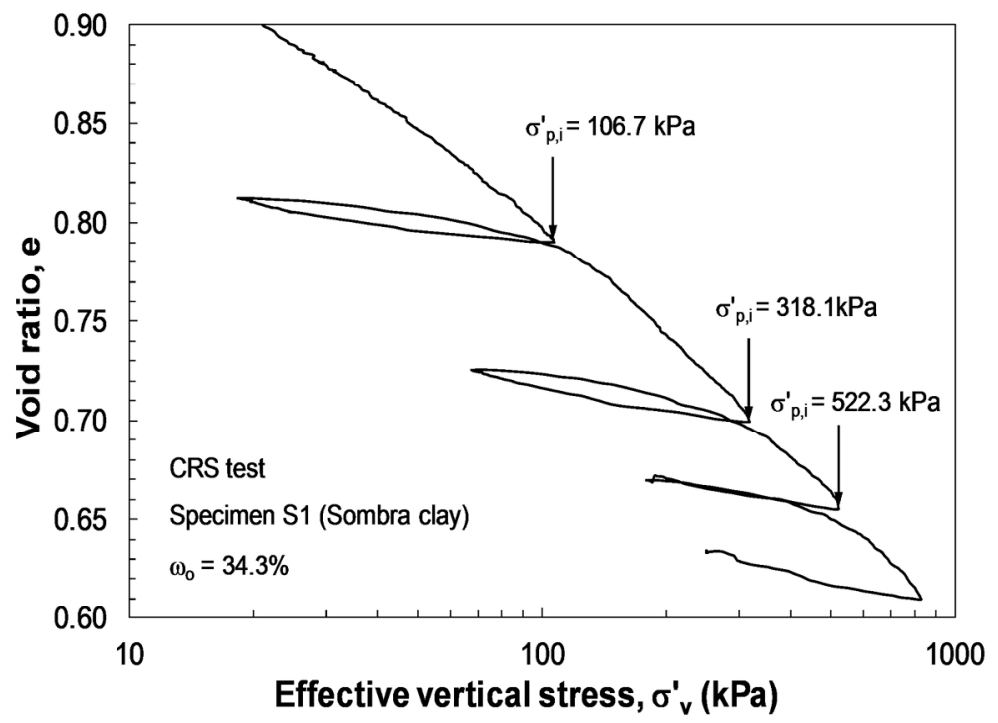

(b)

Fig. 1: EOP consolidation curve for CRS consolidation tests $\mathrm{P} 1$ and $\mathrm{S} 1$ and the imposed pre-consolidation pressures $\left(\sigma_{p, i}^{\prime}\right)$

$142 \times 223 \mathrm{~mm}(300 \times 300 \mathrm{DPI})$ 


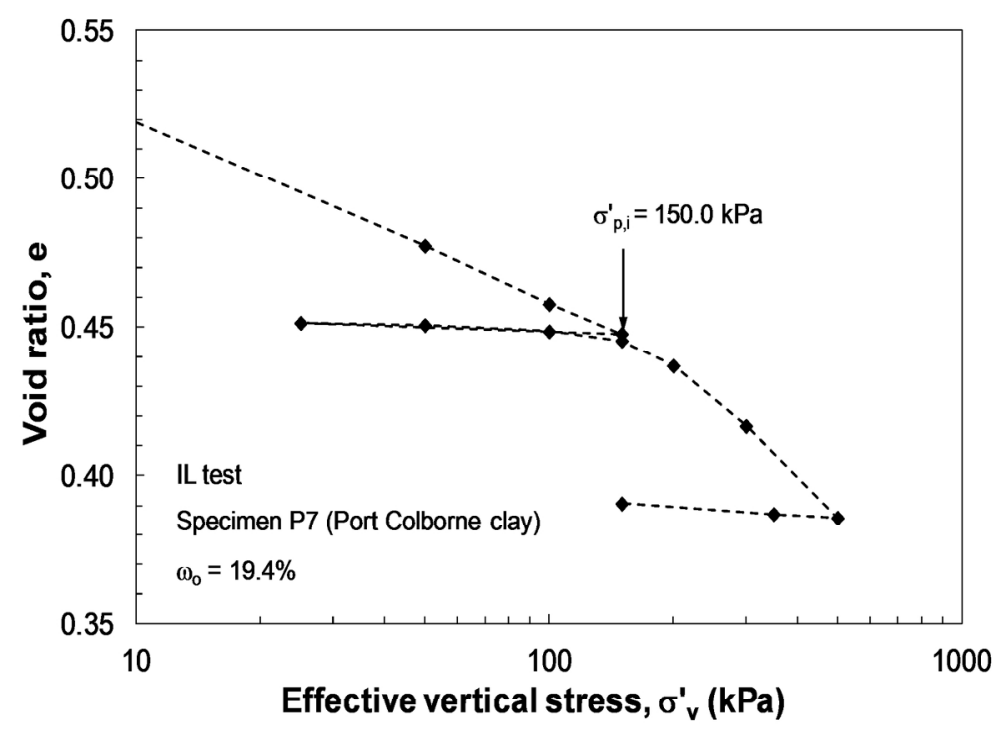

(a)

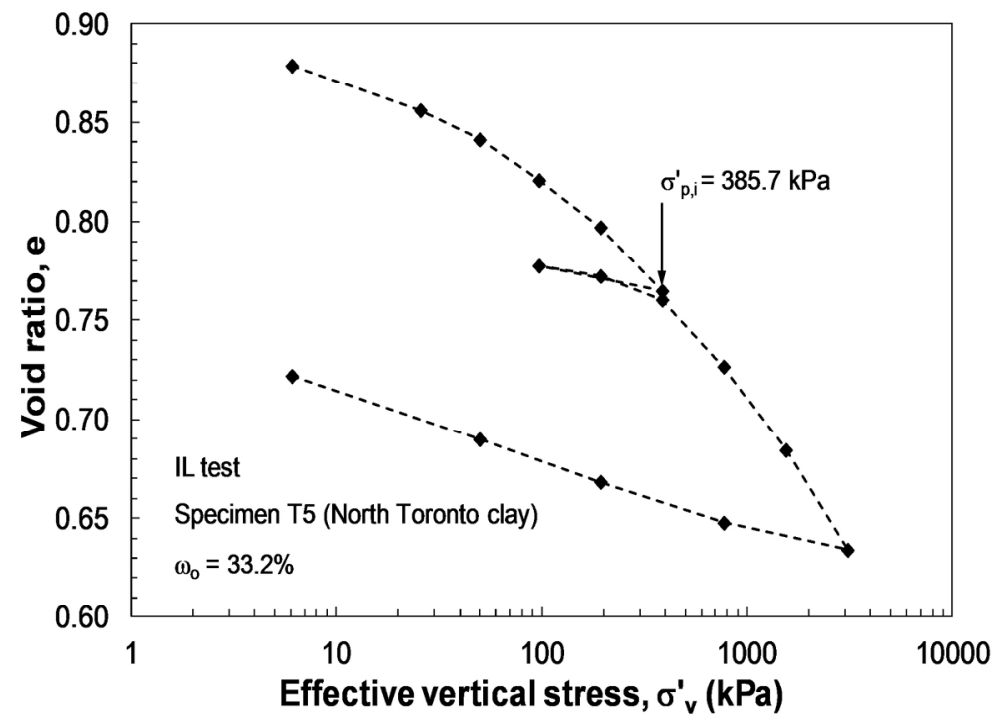

(b)

Fig. 2: EOP consolidation curve for IL consolidation tests P7 and T5 and the imposed pre-consolidation pressures $\left(\sigma_{p, i}^{\prime}\right)$

$142 \times 223 \mathrm{~mm}(300 \times 300 \mathrm{DPI})$ 

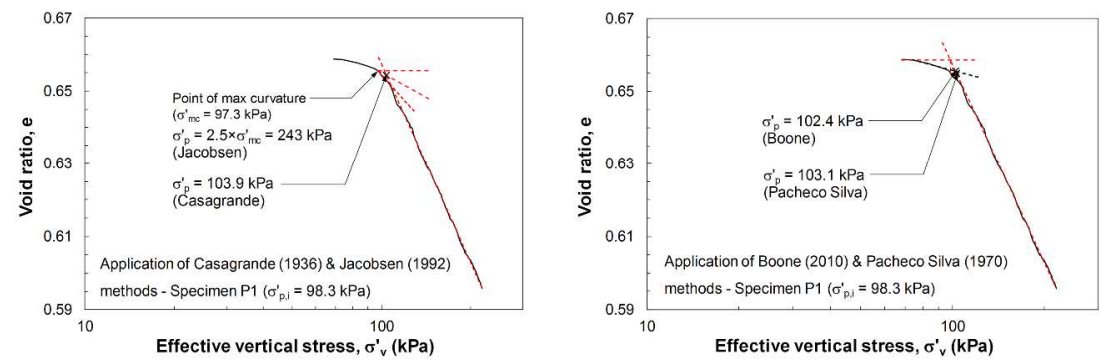

(a)

(b)
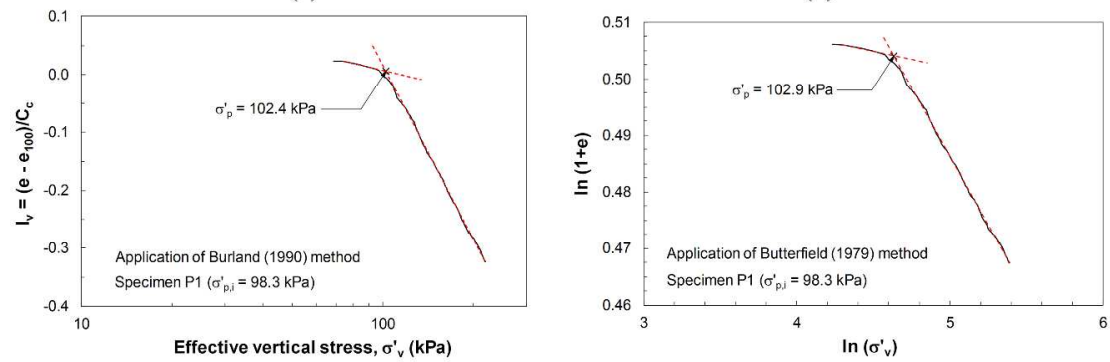

(c)

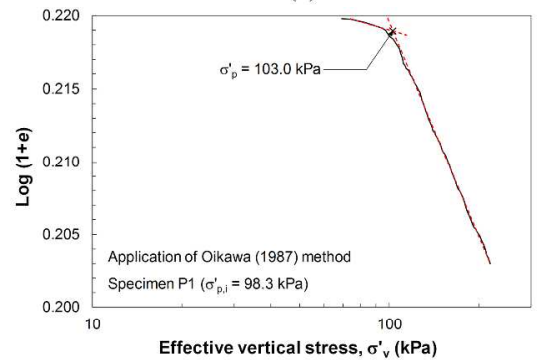

(d)

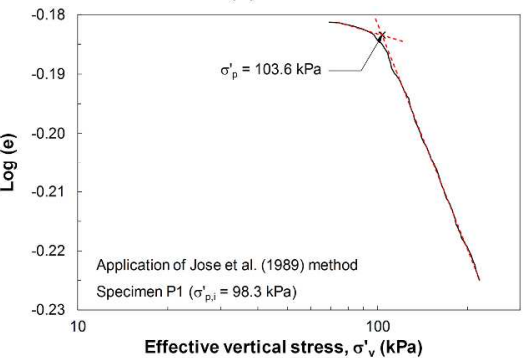

(e)

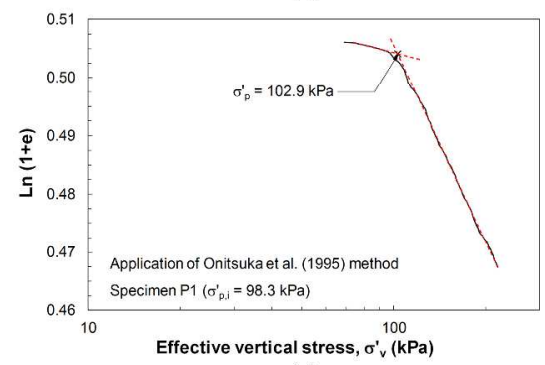

(g)

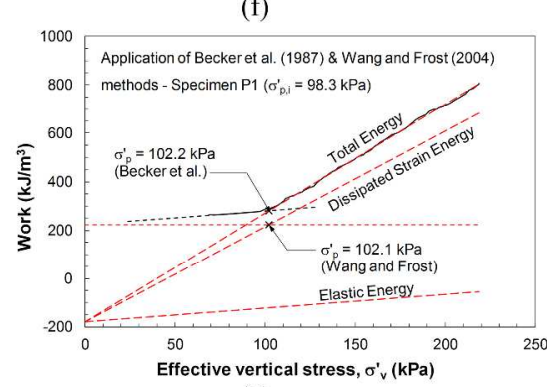

(h)

Fig. 3: Applications of (a) Casagrande (1936) \& Jacobsen (1992), (b) Boone (2010) \& Pacheco Silva (1970), (c) Burland (1990), (d) Butterfield (1979), (e) Oikawa (1987), (f) Jose et al. (1989), (g) Onitsuka et al. (1995), (h) Becker et al. (1987) \& Wang and Frost (2004) methods for estimating $\sigma_{p}^{\prime}$ in CRS specimen P1 subjected to $\sigma_{p, i}^{\prime}=98.3 \mathrm{kPa}$

$273 \times 387 \mathrm{~mm}(300 \times 300 \mathrm{DPI})$ 

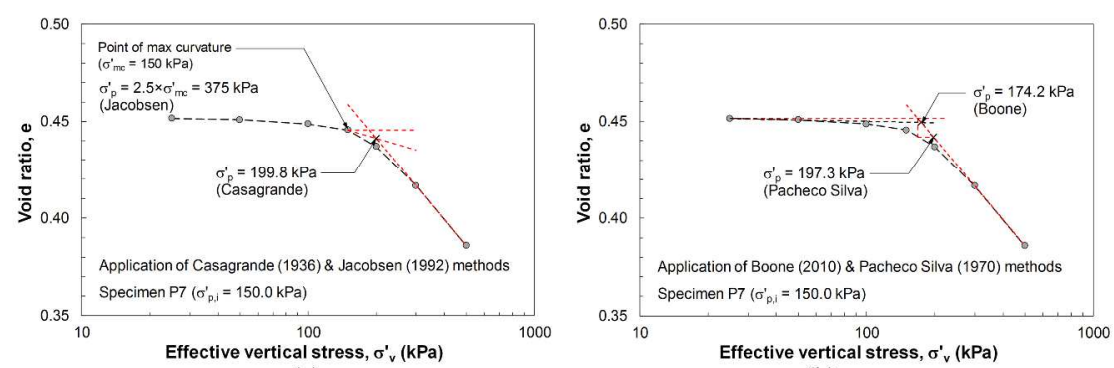

(a)

(b)
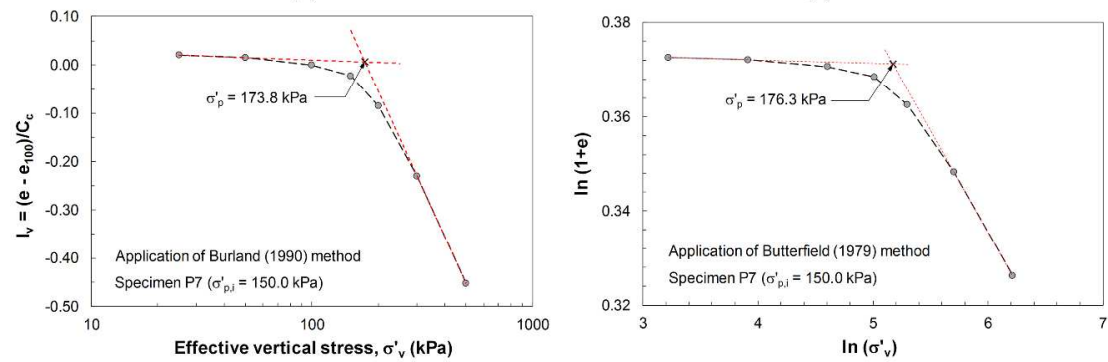

(c)

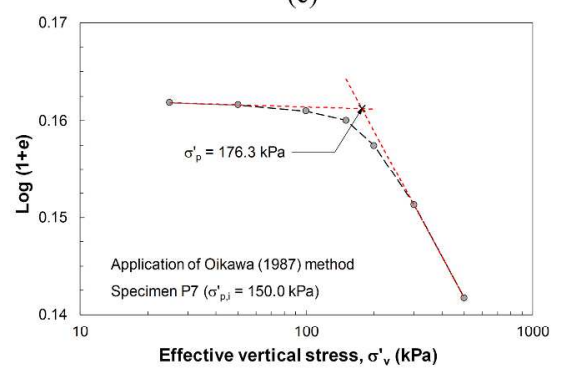

(d)

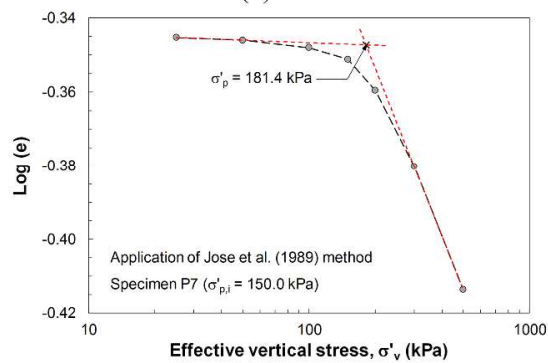

(e)

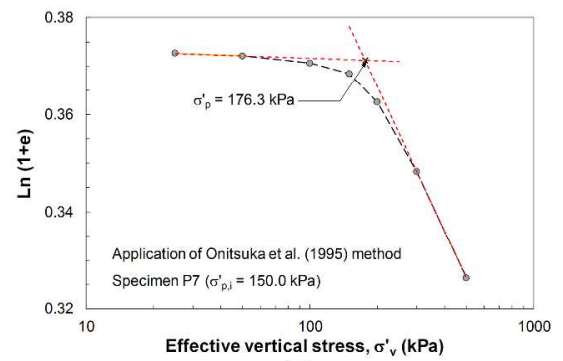

(g)

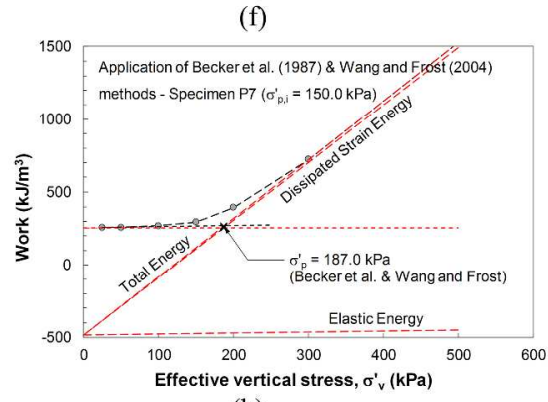

(h)

Fig. 4: Applications of (a) Casagrande (1936) \& Jacobsen (1992), (b) Boone (2010) \& Pacheco Silva (1970), (c) Burland (1990), (d) Butterfield (1979), (e) Oikawa (1987), (f) Jose et al. (1989), (g) Onitsuka et al. (1995), (h) Becker et al. (1987) \& Wang and Frost (2004) methods for estimating $\sigma^{\prime}{ }_{p}$ in IL specimen P7 subjected to $\sigma_{p, i}^{\prime}=150.0 \mathrm{kPa}$

$273 \times 387 \mathrm{~mm}(300 \times 300 \mathrm{DPI})$ 


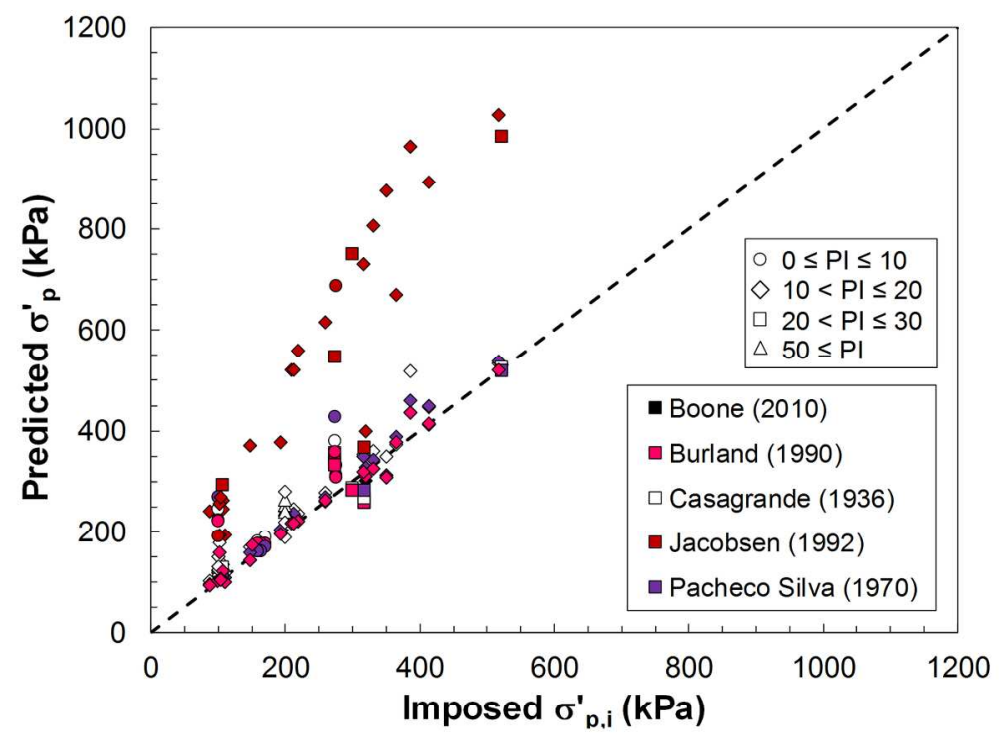

(a)

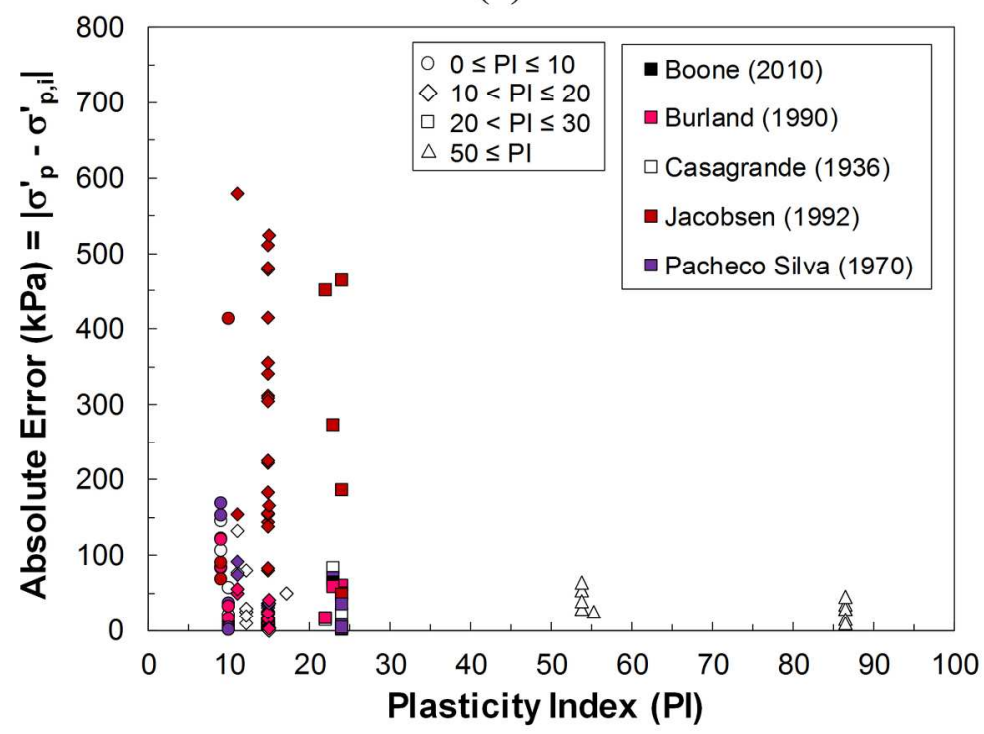

(b)

Fig. 5: Comparisons of $(a) \sigma_{p, i}^{\prime}$ with predictions, and $(b)$ the ranges of absolute errors with PI for the semilogarithmic methods

$142 \times 224 \mathrm{~mm}(300 \times 300 \mathrm{DPI})$ 


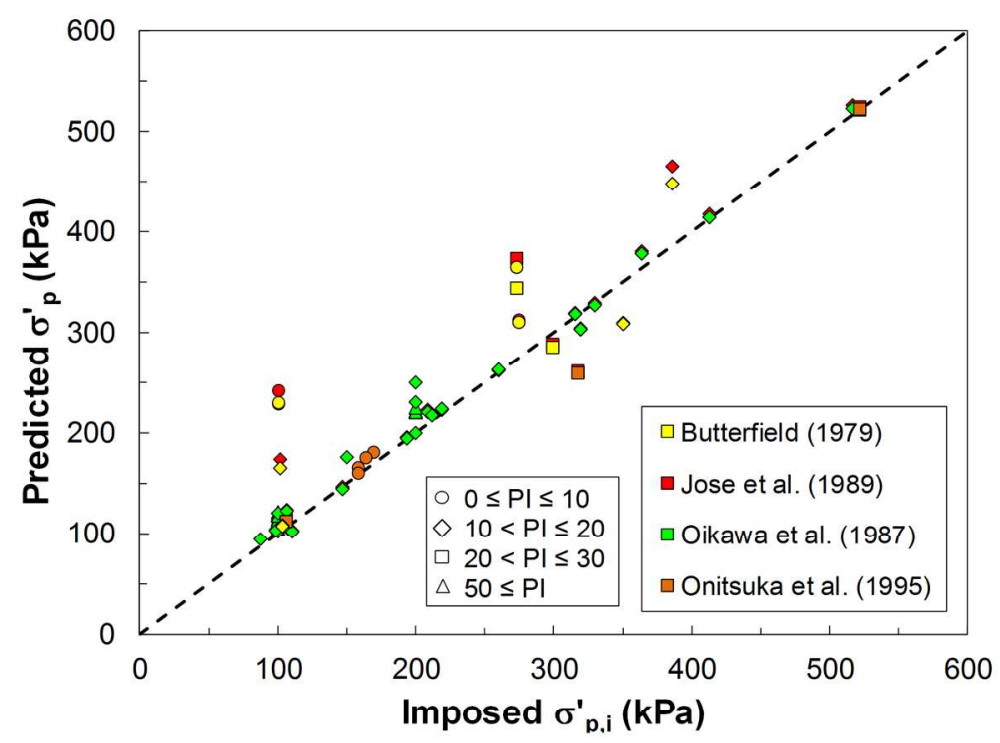

(a)

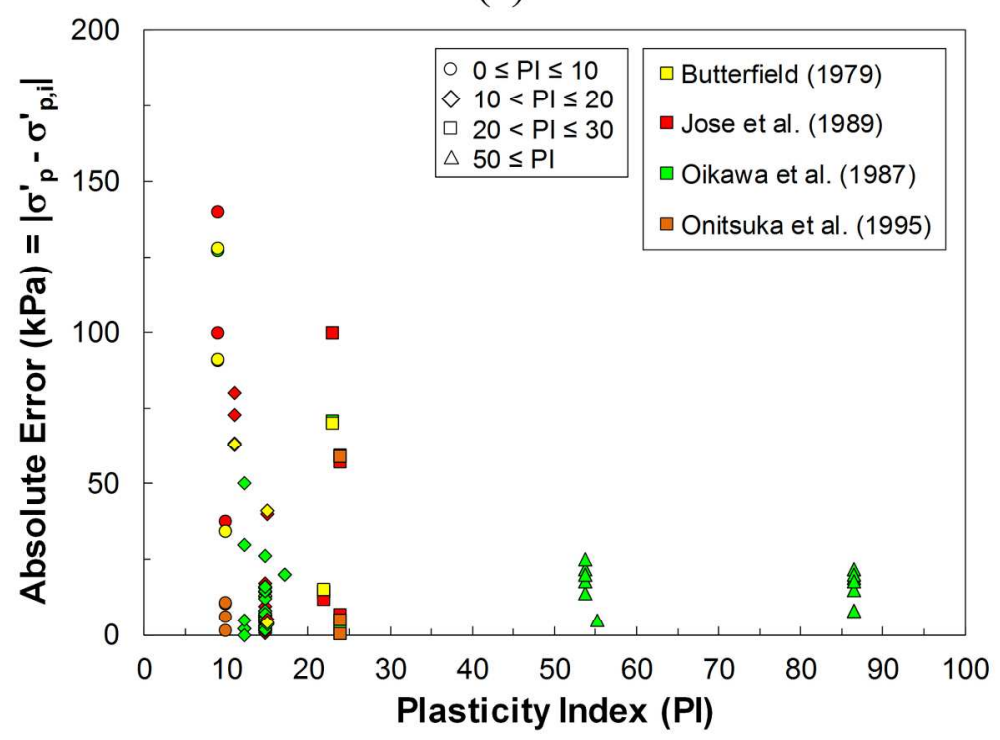

(b)

Fig. 6: Comparisons of $(a) \sigma_{p, i}^{\prime}$ with predictions, and (b) the ranges of absolute errors with PI for the bilogarithmic methods

$141 \times 223 \mathrm{~mm}$ ( $300 \times 300$ DPI) 


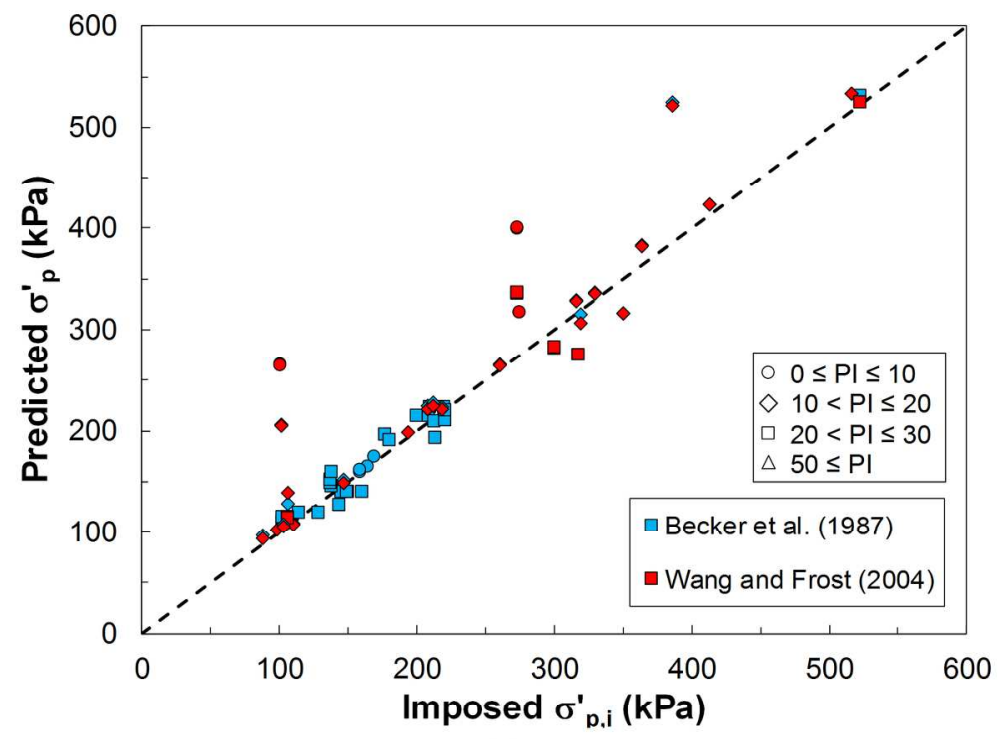

(a)

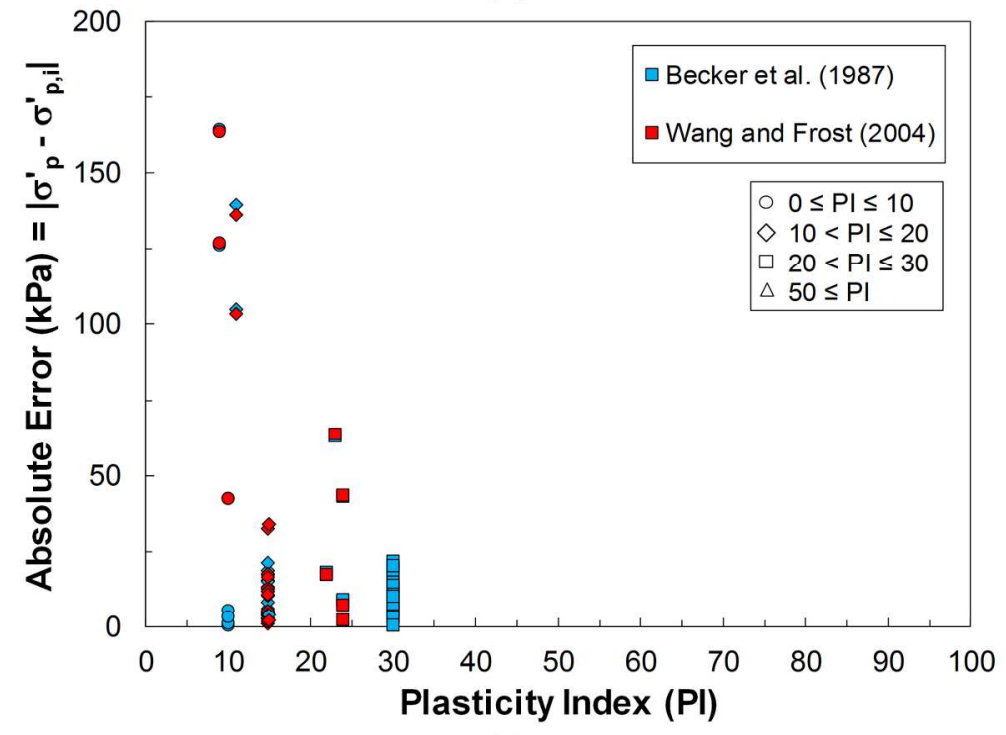

(b)

Fig. 7: Comparisons of $(a) \sigma_{p, i}^{\prime}$ with predictions, and $(b)$ the ranges of absolute errors with PI for the strain energy methods

$141 \times 223 \mathrm{~mm}(300 \times 300 \mathrm{DPI})$ 


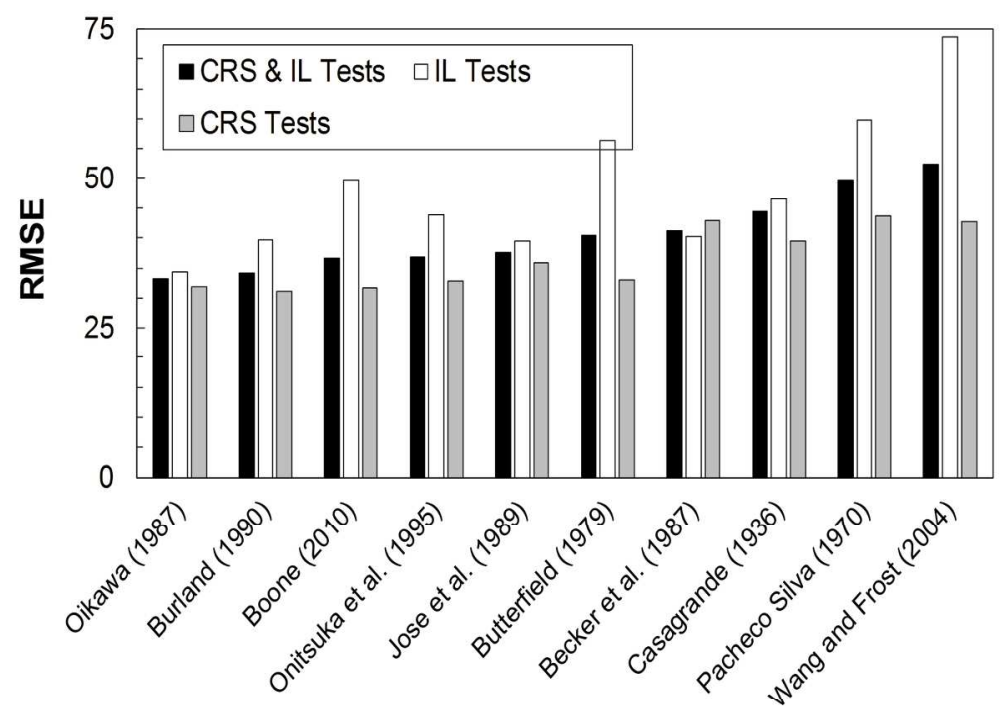

(a)

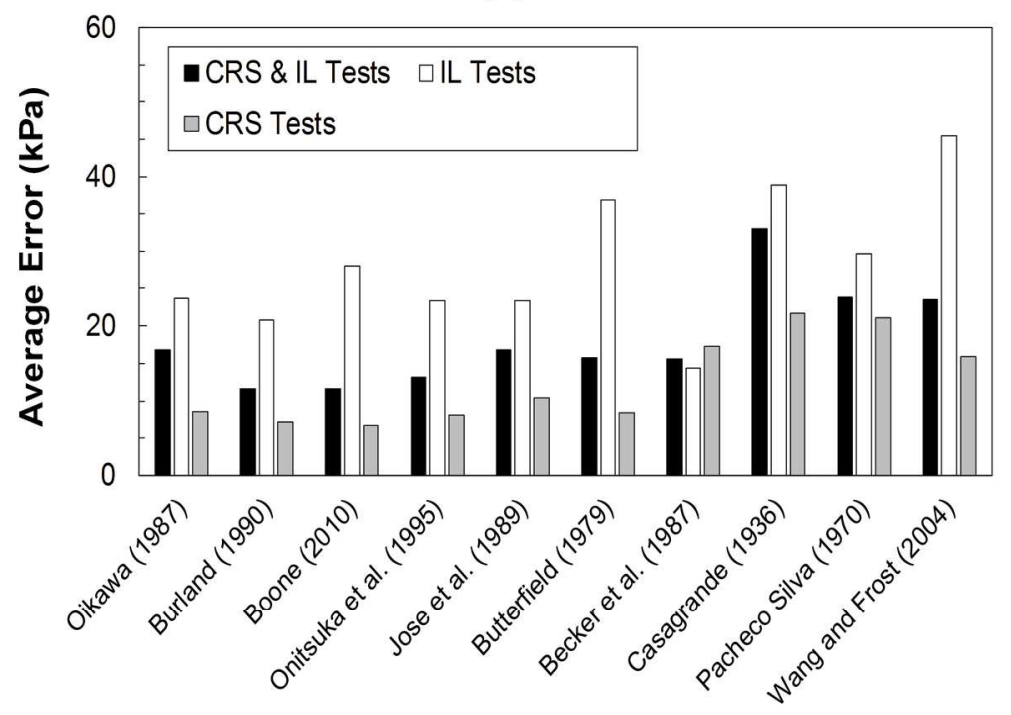

(b)

Fig. 8: Comparison of (a) RMSE and (b) average errors of different methods in predicting $\sigma_{p}^{\prime}$ from CRS and IL tests.

$142 \times 224 \mathrm{~mm}(300 \times 300 \mathrm{DPI})$ 
Table 1: Summary of methods for predicting $\sigma_{p}^{\prime}$ from consolidation tests data

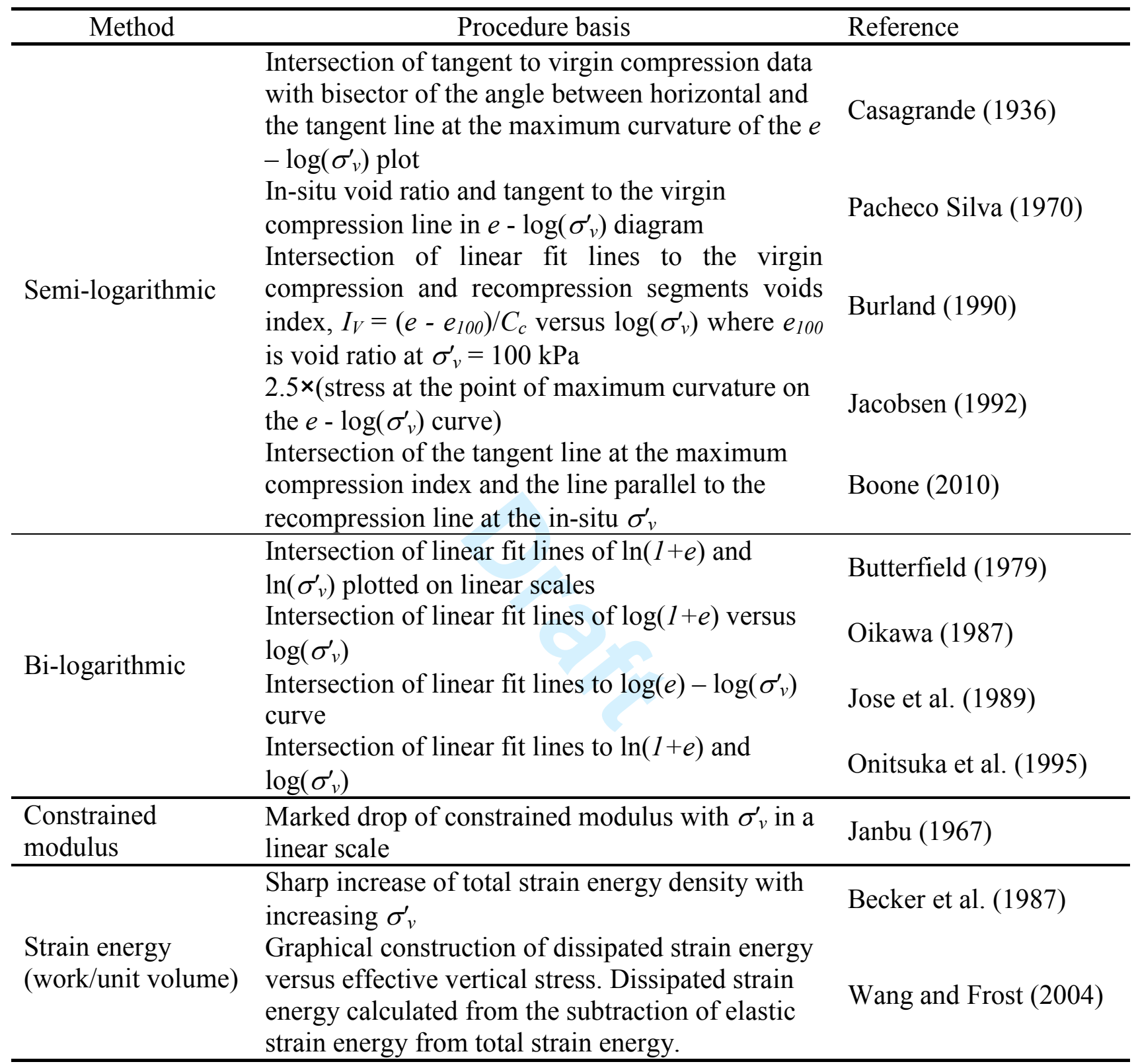


Table 2: Basic characteristics of the clay samples used in this study

\begin{tabular}{lccccc}
\hline Clay & Silt $(\mathbf{\%})$ & Clay (\%) & LL & PL & PI \\
\hline Port Colborne clay & 93.3 & 6.7 & 35.1 & 20.3 & 14.8 \\
Sombra clay & 71.0 & 29.0 & 46.0 & 22.0 & 24.0 \\
North Toronto clay & $55-87$ & $12-45$ & $32-48$ & $11-23$ & $9-23$ \\
\hline
\end{tabular}


Table 3: Characteristics and $\sigma_{p}^{\prime}$ imposted in the experiments of this study

\begin{tabular}{|c|c|c|c|c|c|}
\hline Test & Soil & Specimen & $\omega_{o}(\%)$ & Test No. & $\begin{array}{c}\text { Imposed } \sigma_{p, i}^{\prime} \\
(\mathrm{kPa})\end{array}$ \\
\hline \multirow{23}{*}{ CRS } & \multirow{17}{*}{ Port Colborne clay } & \multirow{3}{*}{ P1 } & \multirow{3}{*}{26.9} & 1 & 98.3 \\
\hline & & & & 2 & 218.6 \\
\hline & & & & 3 & 330.0 \\
\hline & & \multirow{2}{*}{$\mathrm{P} 2$} & \multirow{2}{*}{32.2} & 1 & 107.5 \\
\hline & & & & 2 & 208.4 \\
\hline & & \multirow{2}{*}{ P3 } & \multirow{2}{*}{31.7} & 1 & 147.2 \\
\hline & & & & 2 & 319.4 \\
\hline & & \multirow{3}{*}{ P4 } & \multirow{3}{*}{30.3} & 1 & 87.8 \\
\hline & & & & 2 & 193.6 \\
\hline & & & & 3 & 315.7 \\
\hline & & \multirow{4}{*}{ P5 } & \multirow{4}{*}{40.2} & 1 & 109.8 \\
\hline & & & & 2 & 211.5 \\
\hline & & & & 3 & 363.6 \\
\hline & & & & 4 & 516.2 \\
\hline & & \multirow{3}{*}{ P6 } & \multirow{3}{*}{26.8} & 1 & 106.5 \\
\hline & & & & 2 & 260.1 \\
\hline & & & & 3 & 412.9 \\
\hline & \multirow{3}{*}{ Sombra clay } & \multirow{3}{*}{$\mathrm{S} 1$} & & 1 & 106.7 \\
\hline & & & 34.3 & 2 & 318.1 \\
\hline & & & & 3 & 522.3 \\
\hline & \multirow{3}{*}{ North Toronto Clay } & $\mathrm{T} 1$ & 32.5 & 1 & 101.4 \\
\hline & & $\mathrm{T} 2$ & 30.9 & 1 & 103.3 \\
\hline & & $\mathrm{T} 3$ & 28.3 & 1 & 100.9 \\
\hline \multirow{7}{*}{ IL } & Port Colborne clay & P7 & 19.4 & 1 & 150.0 \\
\hline & \multirow{6}{*}{ North Toronto Clay } & T4 & 35.4 & 1 & 273.2 \\
\hline & & T5 & 33.2 & 1 & 385.7 \\
\hline & & T6 & 31.0 & 1 & 350.0 \\
\hline & & $\mathrm{T} 7$ & 39.5 & 1 & 273.2 \\
\hline & & T8 & 28.4 & 1 & 275.0 \\
\hline & & T9 & 51.7 & 1 & 300.0 \\
\hline
\end{tabular}


Table 4: Summary of pre-consolidation pressures obtained using the semi-logarithmic predictive methods

\begin{tabular}{|c|c|c|c|c|c|c|}
\hline \multirow[b]{2}{*}{$\begin{array}{c}\sigma_{p, i}^{\prime} \\
(\mathrm{kPa})\end{array}$} & \multirow[b]{2}{*}{ PI } & \multicolumn{5}{|c|}{$\sigma_{p}^{\prime}(\mathrm{kPa})$} \\
\hline & & $\begin{array}{l}\text { Boone } \\
(2010)\end{array}$ & $\begin{array}{c}\text { Burland } \\
\text { (1990) }\end{array}$ & $\begin{array}{c}\text { Casagrande } \\
(1936)\end{array}$ & $\begin{array}{c}\text { Jacobsen } \\
(1992)\end{array}$ & $\begin{array}{c}\text { Pacheco } \\
\text { Silva (1970) }\end{array}$ \\
\hline 98.3 & 14.8 & 102 & 102 & 104 & 243 & 103 \\
\hline 218.6 & 14.8 & 222 & 222 & 236 & 559 & 226 \\
\hline 330.0 & 14.8 & 326 & 326 & 361 & 808 & 342 \\
\hline 107.5 & 14.8 & 104 & 104 & 120 & 245 & 112 \\
\hline 208.4 & 14.8 & 220 & 217 & 234 & 521 & 224 \\
\hline 147.2 & 14.8 & 144 & 144 & 170 & 370 & 159 \\
\hline 319.4 & 14.8 & 303 & 310 & 311 & 400 & 328 \\
\hline 87.8 & 14.8 & 94 & 94 & 103 & 242 & 95 \\
\hline 193.6 & 14.8 & 195 & 195 & 203 & 377 & 204 \\
\hline 315.7 & 14.8 & 318 & 318 & 353 & 731 & 350 \\
\hline 109.8 & 14.8 & 101 & 101 & 117 & 193 & 109 \\
\hline 211.5 & 14.8 & 217 & 217 & 246 & 521 & 238 \\
\hline 363.6 & 14.8 & 378 & 378 & 373 & 669 & 389 \\
\hline 516.2 & 14.8 & 520 & 521 & 534 & 1027 & 539 \\
\hline 106.5 & 14.8 & 122 & 122 & 134 & 262 & 124 \\
\hline 260.1 & 14.8 & 261 & 263 & 278 & 615 & 270 \\
\hline 412.9 & 14.8 & 413 & 415 & 447 & 894 & 450 \\
\hline 106.7 & 24.0 & 110 & 110 & 129 & 292 & 114 \\
\hline 318.1 & 24.0 & 257 & 258 & 267 & 366 & 282 \\
\hline 522.3 & 24.0 & 520 & 523 & 525 & 985 & 518 \\
\hline 101.4 & 10.0 & 158 & 158 & 179 & 255 & 194 \\
\hline 103.3 & 10.0 & 106 & 106 & 108 & 269 & 105 \\
\hline 100.9 & 12.0 & 223 & 221 & 246 & 191 & 270 \\
\hline 150.0 & 14.8 & 174 & 174 & 200 & 375 & 197 \\
\hline 273.2 & 19.0 & 357 & 358 & 380 & 342 & 426 \\
\hline 385.7 & 11.0 & 436 & 436 & 518 & 964 & 461 \\
\hline 350.0 & 15.0 & 308 & 308 & 350 & 875 & 313 \\
\hline 273.2 & 23.0 & 337 & 332 & 357 & 546 & 343 \\
\hline 275.0 & 12.0 & 307 & 307 & 332 & 688 & 312 \\
\hline 300.0 & 22.0 & 283 & 283 & 286 & 750 & 283 \\
\hline
\end{tabular}


Table 5: Summary of pre-consolidation pressures obtained using the bi-logarithmic predictive methods

\begin{tabular}{cccccc}
\hline$\sigma_{p, i}^{\prime}$ & PI & Butterfield & \multicolumn{3}{c}{$\sigma_{p}^{\prime}(\mathrm{kPa})$} \\
$(\mathrm{kPa})$ & & $(1979)$ & $(1989)$ & $\begin{array}{c}\text { Oikawa } \\
(1987)\end{array}$ & $\begin{array}{c}\text { Onitsuka et al. } \\
(1995)\end{array}$ \\
\hline 98.3 & 14.8 & 103 & 104 & 103 & 103 \\
218.6 & 14.8 & 222 & 224 & 224 & 223 \\
330.0 & 14.8 & 329 & 329 & 328 & 327 \\
107.5 & 14.8 & 105 & 106 & 105 & 105 \\
208.4 & 14.8 & 222 & 223 & 221 & 221 \\
147.2 & 14.8 & 145 & 147 & 145 & 145 \\
319.4 & 14.8 & 303 & 305 & 303 & 304 \\
87.8 & 14.8 & 94 & 95 & 94 & 94 \\
193.6 & 14.8 & 195 & 196 & 195 & 195 \\
315.7 & 14.8 & 319 & 320 & 319 & 319 \\
109.8 & 14.8 & 102 & 103 & 102 & 102 \\
211.5 & 14.8 & 219 & 219 & 218 & 218 \\
363.6 & 14.8 & 379 & 380 & 379 & 379 \\
516.2 & 14.8 & 523 & 526 & 523 & 523 \\
106.5 & 14.8 & 122 & 124 & 123 & 123 \\
260.1 & 14.8 & 263 & 262 & 263 & 261 \\
412.9 & 14.8 & 414 & 417 & 415 & 414 \\
106.7 & 24.0 & 112 & 113 & 112 & 112 \\
318.1 & 24.0 & 259 & 261 & 259 & 259 \\
522.3 & 24.0 & 522 & 524 & 521 & 522 \\
101.4 & 10.0 & 165 & 174 & 165 & 165 \\
103.3 & 10.0 & 108 & 109 & 107 & 107 \\
100.9 & 12.0 & 229 & 241 & 228 & 228 \\
150.0 & 14.8 & 176 & 181 & 176 & 176 \\
273.2 & 19.0 & 364 & 373 & 364 & 364 \\
385.7 & 11.0 & 448 & 466 & 448 & 448 \\
350.0 & 15.0 & 309 & 310 & 309 & 309 \\
273.2 & 23.0 & 343 & 373 & 344 & 344 \\
275.0 & 12.0 & 309 & 313 & 309 & 309 \\
300.0 & 22.0 & 285 & 288 & 286 & 286 \\
\hline & & & & &
\end{tabular}


Table 6: Summary of pre-consolidation pressures obtained using the strain energy predictive methods

\begin{tabular}{|c|c|c|c|}
\hline \multirow{2}{*}{$\begin{array}{c}\sigma_{p, i}^{\prime} \\
(\mathrm{kPa})\end{array}$} & \multirow[b]{2}{*}{ PI } & \multicolumn{2}{|c|}{$\sigma_{p}^{\prime}(\mathrm{kPa})$} \\
\hline & & $\begin{array}{c}\text { Becker et al. } \\
(1987)\end{array}$ & $\begin{array}{c}\text { Wang and Frost } \\
(2004)\end{array}$ \\
\hline 98.3 & 14.8 & 102 & 102 \\
\hline 218.6 & 14.8 & 223 & 221 \\
\hline 330.0 & 14.8 & 336 & 335 \\
\hline 107.5 & 14.8 & 110 & 111 \\
\hline 208.4 & 14.8 & 224 & 221 \\
\hline 147.2 & 14.8 & 152 & 148 \\
\hline 319.4 & 14.8 & 316 & 306 \\
\hline 87.8 & 14.8 & 96 & 93 \\
\hline 193.6 & 14.8 & 199 & 198 \\
\hline 315.7 & 14.8 & 329 & 328 \\
\hline 109.8 & 14.8 & 109 & 108 \\
\hline 211.5 & 14.8 & 227 & 224 \\
\hline 363.6 & 14.8 & 383 & 382 \\
\hline 516.2 & 14.8 & 534 & 533 \\
\hline 106.5 & 14.8 & 128 & 139 \\
\hline 260.1 & 14.8 & 266 & 264 \\
\hline 412.9 & 14.8 & 423 & 424 \\
\hline 106.7 & 24.0 & 115 & 114 \\
\hline 318.1 & 24.0 & 275 & 275 \\
\hline 522.3 & 24.0 & 531 & 525 \\
\hline 101.4 & 10.0 & 206 & 205 \\
\hline 103.3 & 10.0 & 107 & 106 \\
\hline 100.9 & 12.0 & 265 & 264 \\
\hline 150.0 & 14.8 & 187 & 187 \\
\hline 273.2 & 19.0 & 399 & 400 \\
\hline 385.7 & 11.0 & 525 & 522 \\
\hline 350.0 & 15.0 & 316 & 316 \\
\hline 273.2 & 23.0 & 336 & 337 \\
\hline 275.0 & 12.0 & 318 & 318 \\
\hline 300.0 & 22.0 & 282 & 283 \\
\hline
\end{tabular}


Table 7: Comparison of accuracy and RMSE values of the empirical methods evaluated in this study

\begin{tabular}{clcccc}
\hline $\begin{array}{c}\text { Accuracy } \\
\text { ranking }\end{array}$ & Method & $\begin{array}{c}\text { No. of } \\
\text { Analysis }\end{array}$ & $\begin{array}{c}\text { Average } \\
\text { Error (kPa) }\end{array}$ & $\begin{array}{c}\text { Error Range } \\
\text { (kPa) }\end{array}$ & RMSE \\
\hline $\mathbf{1}$ & Oikawa (1987) & 55 & 16.8 & 127.1 to -59.2 & 33.2 \\
$\mathbf{2}$ & Burland (1990) & 34 & 11.6 & 120.3 to -60.6 & 34.1 \\
$\mathbf{3}$ & Boone (2010) & 30 & 11.7 & 210.0 to -60.7 & 36.6 \\
$\mathbf{4}$ & Onitsuka et al. (1995) & 34 & 13.1 & 127.3 to -59.0 & 36.8 \\
$\mathbf{5}$ & Jose et al. (1989) & 45 & 16.8 & 139.9 to -57.1 & 37.7 \\
$\mathbf{6}$ & Butterfield (1979) & 31 & 15.8 & 127.8 to -59.0 & 40.3 \\
$\mathbf{7}$ & Becker et al. (1987) & 58 & 15.6 & 164.1 to -43.2 & 41.2 \\
$\mathbf{8}$ & Casagrande (1936) & 75 & 33.1 & 145.4 to -50.7 & 44.3 \\
$\mathbf{9}$ & Pacheco Silva (1970) & 34 & 23.9 & 168.9 to -36.6 & 49.5 \\
$\mathbf{1 0}$ & Wang and Frost (2004) & 31 & 23.5 & 163.5 to -43.5 & 52.5 \\
$\mathbf{1 1}$ & Jacobsen (1992) & 30 & 276.9 & 578.7 to -48.3 & 317.7 \\
\hline
\end{tabular}

